MATEC Web of Conferences 15, 01030 (2014)

DOI: $10.1051 /$ matecconf/ 20141501030

(C) Owned by the authors, published by EDP Sciences, 2014

\title{
Complexity in Managing Refurbishment Design Process: Malaysian Experience
}

\author{
A.S. $\mathrm{Ali}^{1}$ \\ ${ }^{1}$ Centre for Construction, Building and Urban Studies, Faculty of Built Environment, University of \\ Malaya, 50603 Kuala Lumpur, Malaysia.
}

\begin{abstract}
In Malaysia, building refurbishment is expected to become more important in the next five years. This is due to largest government allocations for refurbishment works in ninth and tenth Malaysian Plan and high demand for refurbishment works. The investigation also introduced the functions of integrative mechanisms, which consist of coordination devices and the degree of involvement of key participants in decisionmaking, as a means to integrate management into the design process. This is paramount in order to increase information-processing capacity during the design process. Seven (7) dominant factors were identified concerning with the design process of refurbishment projects. The variables are: availability of design information, statutory requirements, clients' attributes, clients' needs, design fees, material availability and ease of access. The greater part of design process suffers from uncertainty nature of the projects. Almost half of refurbishment projects prepare design with less than 70 percent information available. The design performance recorded more than three-quarters of refurbishment projects exceed the targeted design time and cost. It was also found that integrative mechanisms contribute toward the improvement of the design performance. In addition, a high degree of involvement during the construction stage could improve refurbishment design performance. From the findings, it could be concluded that the major part of the design process of refurbishment projects suffered from the uncertain nature of the projects. The implementation of integrative mechanisms indicated the possibility of improving some of the design performance.
\end{abstract}

\section{Introduction}

The Malaysian construction sector has performed quite inconsistently over the last 8 years. The output mostly consisted of residential and infrastructure construction activities. However, the output of the local construction industry started to decline in 2005 and 2006. This was mostly due to reduced government spending in the construction sector. The sector however, achieved an output worth more than RM 50 million in 2007 due to bigger government allocation in the construction industry, especially for the repair and maintenance sector. The slightly decrease in construction output in 2006 is not influenced the refurbishment activity. Figure 1 shows the output for refurbishment projects since year 2002 to 2009. Figure 1 shows a generally increasing trend, except for 2004 when output for refurbishment projects declined. However, the refurbishment activities picked up in the following year 2005 even though the overall construction output showed a slight decrease. 
This was due to the government policy of putting more emphasis on repair and maintenance activities, rather than on new construction projects.

The trend is expected to continue in the future since more money has been allocated for repair and maintenance in the ninth Malaysian Plan.

It is interesting to note that even though the trend for construction output has remained almost constant, the pattern for refurbishment project shows an increase. This indicates the importance of refurbishment projects in the Malaysia construction industry.

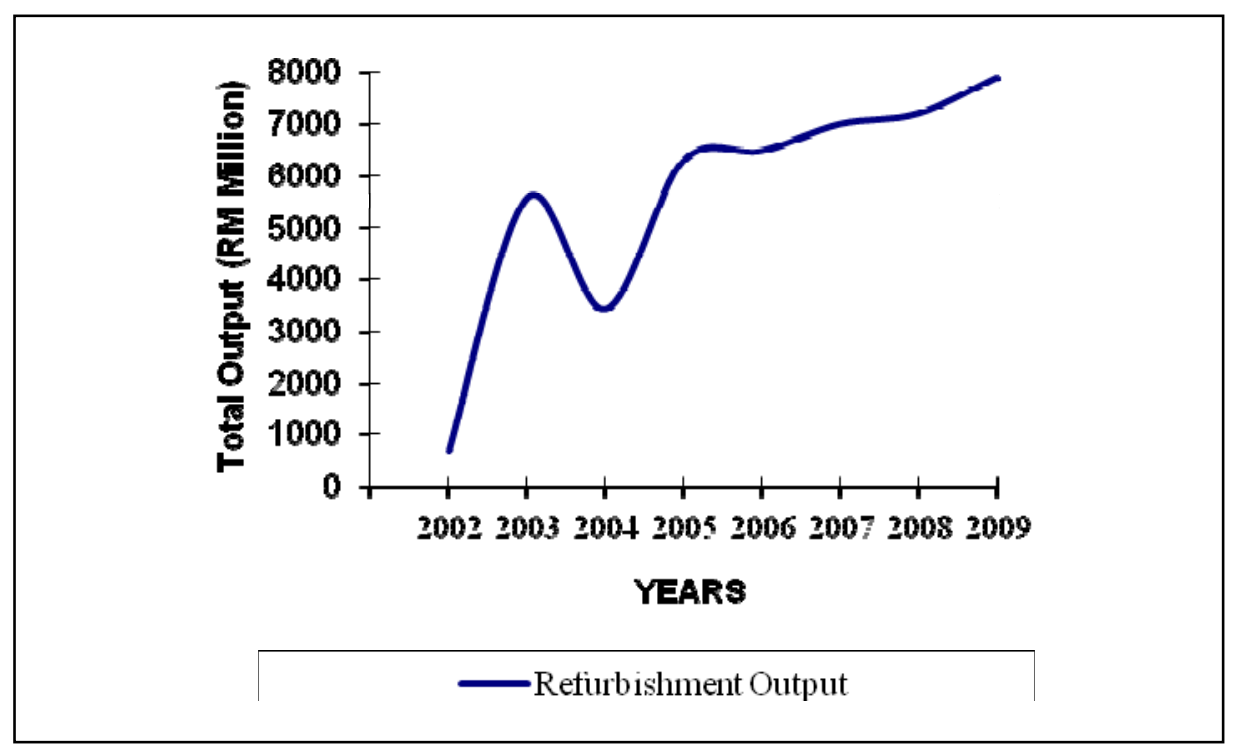

Figure 1: Refurbishment Projects Output in Malaysia

In ninth Malaysia Plan, the construction sector has an average growth of 3.5 percent per annum, compared with only 0.5 percent average growth during eighth Malaysian Plan. Besides civil engineering infrastructure projects, the residential sector is forecast to become the main contributor to growth. One of the largest allocations is for the construction sector, in which the government will inject almost 19 billion Ringgit Malaysia during the next five years. This allocation includes provision for infrastructure, building, and repair and maintenance projects. The development plan allocation for repair and maintenance works increased from RM 296 million during the Eighth Malaysian Plan to RM 1079 million in the Ninth Malaysian Plan [1]. Hence, it is expected that refurbishment work will become more important in the future.

\section{The Design Process of Refurbishment Projects}

Many management authors agree on the importance of the design process towards the success of construction projects. Even though design cost contributes only about 10 percent of total project cost, the performance of the refurbishment projects is much affected by the design process. There is also evidence shows that almost 80 percent of quality problem in a project were contributed by problems in design. Construction performances in the UK have always being reduced by the difficulty of managing the design process. Therefore, management in the design process needs to be improved in order to produce accurate design before work started on site. However, the design process is not easy to manage. The design process is made up of a combination of intense technical and social activities. The In refurbishment, this problem is further compounded by the project uncertainty. Researchers such as Egbu [2], Rahmat [3] and Ali [4] have provided evidence of the complexity of refurbishment 
projects. The problem mainly derives from the lack of information available to perform a task, especially during the initial stage of the design process.

Problems of designing refurbishment projects include the lack of information available about the operating facilities, space limitations and maintaining existing design. The fact is that untimely information makes the design process more complex. Design in refurbishment is different from design in new-build projects because designers have to suit their designs to the existing structure of the building. Because of this, many designers are less interested in being involved in refurbishment work, due to the limitation put on their creativity.

Furthermore, refurbishment projects became even more uncertain when they involve structural modifications, which are sensitive, dangerous and difficult operations. Extra precautions need to be taken when dealing with structural modifications. Temporary supports, which are normally needed for demolition and alteration of building structure, are more widely used in this type of refurbishment work compared with new-build projects. Moreover, the content of services work in refurbishment projects is another major factor that contributes to design uncertainty of refurbishment projects. Hidden items such as piping and electrical cables induce designers to make assumptions on the services routing in their design. As a result, changes of design frequently happen during the construction stage, due to inaccurate routing design.

In the aspect of building regulation, refurbishment design is one of sectors that are affected by the complexities of legislation. Changing and updating some of building regulations by government have also affected approval process in refurbishment projects, especially projects related to conservation. Refurbishment for heritage buildings has to face regulations that are more stringent and must comply with the listed building requirements, which limits the extent of alteration work allowed. The statutory requirements could cause project delays and cost overruns due to adjustments that need to be made to design in order to comply with the regulations.

One of the problems faced by refurbishment designers is to match up the existing material with new designed material. The problem of finding materials contributes to delay in the design and project duration. The availability of refurbishment material for conservation works is uncertain and such materials often take more time to produce because the material is no longer available in the market. Designers need to be knowledgeable in the selection of suitable material, identifying which one is available and compatible during the construction stage. Often, designers of refurbishment projects have to cope with frequent changes due to client requests. This contributes to uncertainty since many unpredictable changes of design occur during the construction stage because the clients suddenly change their preference. There were a greater number of instances of revision work carried out in post-design phases compared to during the design phase of construction projects and the main reason for revision identified was owner-initiated the changes. The uncertainty of design information to designers to produce a refurbishment design always causes incomplete design. Some part of design remained incomplete because knowledge of the effected item could only be revealed during the construction stage. As a result, designers need to make an assumption about the item. This would cause design changes during construction and influence the performance of refurbishment projects.

The uncertainty in refurbishment projects has always been identified as one of the reason for poor project performance. Ali [4] found more than half of refurbishment projects exceeded the original cost. Furthermore, the completeness of design is also an important factor to be considered. The availability design information is important because it will guide the contractor to perform their works on site. However, Rahmat [3] found that the design for refurbishment works was generally to be incomplete. This reflected amount of provisional sum allocated in a contract to cater the uncertainty of design information. The literature review found no systematic research had been carried out on uncertainty during the design process in refurbishment projects. Hence, second objective of this study is to identify the uncertainty variables that affect the design performance.

It is suggested that the management of uncertainty is important for the success of refurbishment projects. Therefore, the rationale for conducting this study is to improve the management of complexity in the design process of refurbishment projects. 


\section{Integrative Mechanism in Refurbishment Projects}

The refurbishment design process is complex due to the fact that it involves multidisciplinary parties in decision making to meet the clients' requirements. The complexity in refurbishment projects is greater when limited information is available, especially in the initial stage of the design process. The differentiation and fragmentation in refurbishment projects is a consequence of the high degree of specialization in design and construction. The participants involved in the project tend to make decisions in their specialised areas without coordinating with other key participants. This causes disintegration of their own tasks in the construction projects, which leads to many problems, such as completeness of design.

Differentiation and fragmentation within an organization demand a high level of integration. Integration refers to coordination or working together among the organization members, a response to differentiation. Hence, it could be argued that integration in the design process is critical to ensure efficient communication flow and to produce complete design. One of the best ways to achieve integration in a project organization is by implementing integrative mechanisms. Integrative mechanisms consist of two elements; namely coordination devices and involvement of key participants in decision-making process. Coordination could be enhanced by using coordination devices such as lateral relations, interpersonal relationships and information technology in managing the design process.

Lateral relations such as meetings and direct contact are important coordination devices in highly uncertain environments. Meeting functions are to coordinate and as a means of conveying information about current progress work and recent design changes. In general, there are two type of meetings in construction project; namely, scheduled and unscheduled meetings. Unscheduled meetings are conducted to discuss emergency issues and to get faster decisions pertaining to the problem. Unscheduled meeting would be useful to handle uncertainty of new discoveries on the site. In addition, direct contact is also an important method of gathering information. Formal contact is more rigid to use in obtaining the information. On the other hand, a more flexible and faster approach could be enjoyed by employing direct informal contact, which includes informal conversations, telephone call or discussions.

Information Technology (IT) in the construction industry functions as an interface tool to improve project integration. The use of an IT support system would enhance interfacing design, communication and the data collection process. IT is not only effective for coordinating people in projects but it also useful for producing faster and accurate designs. Changes in refurbishment design are often substantial due to late discovery of information on site. This requires the design process to be more flexible so that the flow of communication could be more efficient.

Furthermore, the designers need to play an important role in achieving superior design constructability and producing good quality of design. This mostly relies on the experience and knowledge of the designer, which could reduce the amount of design information needed Different designers have different ways to approach their design works and the outcome of the design produced, relied on the ability of the architects involved.

There has been relatively few research carried out which has focused on the involvement of key participants in decision-making in the design process. It could be argued that the best way to manage the uncertainty of refurbishment projects was by having a greater integration of decision making amongst the key participants. The involvement of key participants at all stages of the design process could increase integration in project organization, which in turn could improve design performance.

\section{Conclusions}

Integrative mechanisms combined of coordination devices and involvement of key design participants in decision-making process. It is vital to gear towards improving some of the design performance by increase information processing capacity in refurbishment design process. The inherent uncertainties associated in refurbishment design process causes high risk in decisions to be 
taken. Hence, it is essential for the key design participants to involve outside their own domain and prioritise which design performance need to be achieved. The need to coordinate key design participants requires design team to implement coordination devices. The distinctive feature in the design process of refurbishment projects is conflicting demands. The design process in refurbishment projects requires formal and informal communications, integration and differentiations of tasks, flexible and rigid procedures. The conflicting elements in managing refurbishment design process require the practitioners in Malaysia to handle the problem holistically.

\section{References}

1. Malaysia, Economic Planning Unit, Prime Minister's Department (2006). Ninth Malaysian Plan 2006-2010. Percetakan Nasional Malaysia Berhad, Kuala Lumpur.

2. Egbu, C.O. (1994). Management education and training for refurbishment work within the construction industry, $\mathrm{PhD}$ thesis Department of Civil Engineering, University of Salford, UK.

3. Rahmat, I. (1997). The planning and control process of refurbishment projects, $\mathrm{PhD}$ thesis, University College London, UK.

4. Ali, A.S., Rahmat, I. and Hassan, H. (2008). Involvement of key design participants in refurbishment design process, Facilities, Vol. 26 No. 9/10, pp 389-400. 